\title{
EFEKTIVITAS PENERAPAN GUIDED IMAGERY TERHADAP PENURUNAN RASA NYERI PASIEN GASTRITIS
}

\author{
Sumariadi*, Dewi Simamora, Loni Yanasari Nasution, Rahmad Hidayat, Sunarti \\ Fakultas Keperawatan dan Kebidanan, Universitas Prima Indonesia, Jl. Sekip Jl. Sikambing No.simpang, \\ Sei Putih Timur. I, Medan Petisah, Kota Medan, Sumatera Utara, Indonesia 20111 \\ *sumariadi96@gmail.com
}

\begin{abstract}
ABSTRAK
Gastritis merupakan peradangan pada dinding mukosa lambung dengan tanda dan gejala nyeri. Gastritis atau sering disebut penyakit maag adalah penyakit yang sangat mengganggu aktifitas sehari-hari jika tidak ditangani akan bersifat fatal. Biasanya penyakit gastritis dapat terjadi pada orang-orang yang mempunyai pola makan yang tidak teratur dan sering memakan makanan yang memproduksi asam lambung. Asam lambung yang meningkat akan menyebabkan nyeri pada ulu hati yang dapat ditangani dengan manajemen nyeri, salah satunya adalah guide imagery. Tujuan penelitian untuk mengidentifikasi pengaruh guide imagery terhadap penurunan rasa nyeri pada pasien gastritis. Desain penelitian kuantitatif dengan survey analitik yang melalui pendekatan cross sectional. Populasi dalam penelitian ini adalah seluruh pasien gastritis yang di rawat inap di RSU Royal Prima Medan. Sampel dalam penelitian ini berjumlah 85 responden. Teknik pengambilan sampel yaitu purposive sampling. Pasien akan dilakukan pemeriksaan skala nyeri dengan menggunakan tools numeric sebelum dan sesudah tindakan guide imagery. Analisa data menggunakan paired t test di dapat $\mathrm{p}$-value 0,000. Kesimpulan: Guided imagery berpengaruh terhadap penurunan rasa nyeri pada pasien gastritis.
\end{abstract}

Kata kunci: gastritis; guided imagery; skala nyeri

\section{EFFECT OF GUIDED IMAGERY ON THE REDUCTION OF PATIENTS OF GASTRYSTIC PATIENTS}

\section{ABSTRACT}

Gastritis is an inflammation of the walls of the gastric mucosa with signs and symptoms of pain. Gastritis or often called ulcer disease is a disease that is very disruptive to daily activities if not treated will be fatal. Usually gastritis disease can occur in people who have an irregular diet and often eat foods that produce stomach acid. Increased stomach acid will cause pain in the heart that can be treated with pain management, one of which is guide imagery. The purpose of the study was to identify the influence of guide imagery on decreased pain in gastritis patients. Quantitative research design with analytical surveys through a cross sectional approach. The population in this study was all gastritis patients who were hospitalized at Royal Prima Hospital Medan. The sample in this study amounted to 85 respondents. Technic sampling with purposive sampling. Patients will be examined on a pain scale using tools before and after the guide imagery. Data analysis using paired t test can be p-value 0,000. Conclusion: Guided imagery has an effect on reducing pain in gastritis patients.

Keywords: gastritis; guided imagery; pain scale 


\section{PENDAHULUAN}

Gastritis merupakan peradangan pada dinding mukosa lambung dengan tanda dan gejala nyeri. Gastritis atau sering disebut penyakit maag adalah penyakit yang sangat mengganggu aktifitas sehari-hari jika tidak ditangani akan bersifat fatal. Biasanya penyakit gastritis dapat terjadi pada orang-orang yang mempunyai pola makan yang tidak teratur dan sering memakan makanan yang memproduksi asam lambung (Brunner \& Suddart, 2017).

Menurut Brunner \& Suddart (2017), tanda gejala dari sakit gastritis selain "nyeri di daerah ulu hati adalah mual, muntah kembung dan terasa sesak nafas, nafsu makan menjadi menurun, wajah terlihat pucat, suhu badan meningkat, keluar keringat dingin, pusing dan selalu bersendawa, pada kondisi yang lebih parah bisa terjadi muntah darah".

Menurut World Health Organization (2014), Badan Penelitian yang melakukan tinjauan terhadap 8 negara dunia dan mendapatkan "beberapa hasil persentase dari angka kejadian gastritis di dunia, dimulai dari negara yang angka kejadian penyakit gastritis tertinggi yaitu Amerika dengan persentase mencapai $47 \%$, kemudian diikuti oleh India dengan persentase $43 \%$, lalu beberapa negara lainnya seperti Inggris 22\%, China 31\%, Jepang 14,5\%, Kanada 35\%, Perancis 29,5\%, dan Indonesia 40,8\%"

Insidensi terjadinya penyakit gastritis di Indonesia cukup tinggi, dari sensus yang dilakukan oleh Departemen Kesehatan RI tahun 2013 “angka kejadian gastritis di beberapa kota di Indonesia ada yang tinggi mencapai $91,6 \%$ yaitu di Kota Medan, lalu di beberapa kota lainnya seperti Jakarta 50,0 \%, Denpasar 46,0 \%, Palembang 35,5\%, Bandung 32,5\%,
Aceh $31,7 \%$, Surabaya $31,2 \%$ dan Pontianak 31,1\%".

Salah satu masalah dalam gastritis adalah nyeri. Menurut Kozier bahwa "nyeri merupakan suatu sensasi yang sangat tidak menyenangkan dan bervariasi pada setiap individu yang bisa mempengaruhi pikiran seseorang mengatur aktivitasnya, dan bisa mengubah kehidupan orang tersebut". Masalah ini perlu untuk diungkap melalui komunikasi terapeutik karena nyeri merupakan faktor psikososial yang perlu dikaji perawat secara subjektif dan objektif dalam menilai nyeri (Kozier dalam Patasik, dkk, 2013).

Seorang tenaga medis, khususnya perawat, penting mengetahui dalam menurunkan nyeri melalui manajemen nyeri. Menurut Kozier bahwa "Manajemen nyeri dapat dilakukan secara farmakologi dan nonfarmakologi" Manajemen nyeri nonfarmakologi terdapat berbagai cara, salah satunya adalah dengan menggunakan teknik relaksasi berupa guided imaginary.

Guided imagery merupakan salah satu teknik distraksi nyeri yang bisa digunakan dalam penanganan nyeri, menurunkan tekanan darah, menurunkan kadar kolesterol, glukosa dan meningkatkan aktivitas sel (Belleruth Naparstek, 2017). Guided imagery merupakan suatu teknik dengan menganjurkan pasien untuk mengalihkan pikirannya terhadap sesuatu yang indah sesuai dengan instruksi dari perawat sehingga nyeri yang dialami oleh pasien akan hilang atau berkurang.

Salah satu penelitian yang meneliti tentang guided imagery yang dilakukan oleh Lolo dan Novianty (2018), yang melakukan tindakan guided imagery pada pasien post operasi appendisitis, dengan hasil $\mathrm{p}$ value 0,000 yang 
menyatakan bahwa terdapat pengaruh antara guided imagery terhadap penurunan nyeri.

Penelitian lain yaitu dilakukan oleh Patasik, Tangka \& Rottie (2018), yaitu bahwa "efektifitas teknik relaksasi napas dalam dan guided imagery terhadap penurunan nyeri pada pasien post operasi sectio caesare di Irina D Blu RSUP Prof. DR.R.D. Kandou Manado, dengan hasil p-value 0,000 yang menyatakan intervensi dapat menurunkan intensitas nyeri pada pasien post operasi sectio caesarea". Di RSU Royal Prima Medan, manajemen nyeri hanya difokuskan pada farmakologi dan terapi relaksasi napas dalam. Tujuan penelitian ini adalah untuk menganalisa adanya pengaruh guided imagery terhadap penurunan nyeri pada pasien gastritis di RSU Royal Prima Medan.

\section{HASIL}

Gambaran Karakteristik Responden Pasien Gastritis di RSU Royal Prima Medan

Tabel 1 mayoritas pasien gastritis di RSU Royal prima berjenis kelamin perempuan dengan presentase $71,75 \%$,berusia 18-45 tahun dengan presentase $42,35 \%$, memiliki riwayat pekerjaaan karyawan swasta dengan persentase $34,12 \%$, memiliki pendidikan terakhir SMA dengan persentase 56,47 $\%$, dan lama rawat inap 2 hari dengan persentase 49,41.

Tabel 1.

Responden Pasien Gastritis $(\mathrm{n}=85)$

\begin{tabular}{lcc}
\hline \multicolumn{1}{c}{ Karakteristik Responden } & f & $\%$ \\
\hline Jenis Kelamin & 24 & 28,24 \\
Laki-laki & 61 & 71,76 \\
Perempuan & & \\
\hline Usia & 18 & 21,17 \\
<18 Tahun & 36 & 42,35 \\
18-45 Tahun & 21 & 24,70 \\
>45 Tahun & & \\
Pekerjaan & 7 & 8,24 \\
Mahasiswa Karyawan Swasta & 29 & 34,12 \\
Wiraswasta & 18 & 21,18 \\
PNS & 22 & 25,88 \\
IRT (Ibu Rumah Tangga) & 9 & 10,59 \\
& & \\
\hline Pendidikan Terakhir & 10 & 11,76 \\
SMP & 27 & 31,76 \\
SMA & 48 & 56,47 \\
S1/S2 & & \\
\hline Lama Rawat Inap & 22 & 25,88 \\
1 Hari & 42 & 49,41 \\
2 Hari & 21 & 24,71 \\
3 Hari & & \\
\hline
\end{tabular}


Tabel 2.

Gambaran Skala Nyeri Pasien Gastritis Sebelum dan Sesudah Intervensi

\begin{tabular}{lcc}
\hline \multicolumn{1}{c}{ Kategori } & f & $\%$ \\
\hline Sebelum Intervensi & & \\
Skala Nyeri Ringan & 32 & 37,65 \\
Skala Nyeri Sedang & 47 & 55,29 \\
Skala Nyeri Berat & 6 & 7,06 \\
Sesudah Intervensi & & \\
Skala Nyeri Ringan & 76 & 89,41 \\
Skala Nyeri Sedang & 9 & 10,59 \\
Skala Nyeri Berat & 0 & 0 \\
\hline
\end{tabular}

Tabel 3 Pengaruh Guide Imagery terhadap Penurunan Rasa Nyeri Pasien Gastritis

\begin{tabular}{ccc}
\hline Variabel & $p$-value & Keterangan \\
\hline Sebelum-Sesudah Intervensi Guide Imagery & 0,000 & Ada Pengaruh/ Perbedaan \\
\hline
\end{tabular}

Tabel 2 dapat dijelaskan bahwa skala nyeri pasien gastritis di RSU Royal Prima Sebelum intervensi guide imagery mayorritas merasakan nyeri sedang sekitar 55,29\%, nyeri ringan 37,65\% dan nyeri berat $7,06 \%$. Sedangkan sesudah intervensi mayoritas pasien merasakan penurunan nyeri mayoritas menjadi nyeri ringan $89,41 \%$ dan nyeri sedang $10,59 \%$

Tabel 3 dapat dijelaskan bahwa guided imagery memiliki pengaruh terhadap penurunan rasa nyeri pada pasien gastritis yang dilihat dari uji bivariate dengan paired t test dengan nilai sig. (2tailed) $0,000<0,05$ yang menyatakan bahawa terdapat perbedaan skala nyeri sebelum dan sesudah intervensi.

\section{PEMBAHASAN}

\section{Gambaran Karakteristik Responden} Pasien Gastritis di RSU Royal Prima Medan

Pasien gastritis di RSU Royal Prima Medan berjenis kelamin perempuan dengan presentase $71,75 \%$,berusia 18 45 tahun dengan presentase $42,35 \%$, memiliki riwayat pekerjaaan karyawan swasta dengan persentase $34,12 \%$, memiliki pendidikan terakhir SMA dengan persentase $56,47 \%$, dan lama rawat inap 2 hari dengan persentase 49,41. Mayoritas berjenis kelamin perempuan karena perempuan relatif mengalami kesulitan dalam ketepatan makan dan relatif sering menggunakan makan yang fastfood.

\section{Gambaran Skala Nyeri Pasien Gastritis Sebelum dan Sesudah Intervensi}

Gastritis atau radang pada lambung memiliki ciri khas gejala salah satunya adalah nyeri ulu hati yang dirasakan pasien akibat peradangan yang terjadi pada lambung. Sesuai dengan hasil penelitian di dapatkan pasien dengan gastritis relatif mayoritas mengalami nyeri yang sedang dengan persentase $55,29 \%$, yang mengalami nyeri ringan $37,65 \%$, dan nyeri berat sebanyak $7,09 \%$.

Nyeri yang dialami pasien terjadi karena peradangan yang terjadi pada daerah tukak lambung. Nyeri kerap terjadi terutama pada saat lambung mengalami kekosongan.

Berdasarkan hasil penelitian di dapatkan terdapat perbedaan skala nyeri sebelum dan sesudah dilakukan intervensi berupa guide imagery. Pasien dengan skala 
nyeri berat mengalami penurunan menjadi 0 , pasien dengan nyeri sedang mengalami penurunan menjadi 9 orang dan mengalami nyeri ringan bertambah menjadi 76 orang. Hal ini dikarena terapi guide imagery memiliki pengaruh terhadap penurunan rasa nyeri pada pasien dengan gastritis.

\section{Pengaruh Guide Imagery terhadap Penurunan Rasa Nyeri Pasien Gastritis}

Berdasarkan hasil penelitian terdapat pengaruh antara guide imagery terhadap penurunan rasa nyeri pada pasien gastritis di RSU Royal Prima. Pada penelitian terdapat penurunan nyeri dari mayoritas skala sedang-berat menjadi skala ringan-sedang. Hal ini sesuai dengan hasil penelitian Sembiring dkk (2019), bahwa terdapat pengaruh guide magery terhadap nyeri pasien gastritis di RSU Royal Prima Medan dengan 17 responden dengan nilai sig. 2 tailed $0,000<0,05$. Penelitian lain yang mendukung yaitu penelitian Handayani (2018), bahwa terdapat pengaruh guide imagery terhadap respon nyeri pasien remathoid artritis hasil penelitian ini menunjukkan bahwa terapi relaksasi guided imagery terbukti efektif dalam menurunkan intensitas nyeri pada penderita rheumathoid arthritis di komunitas dengan nilai $\mathrm{p}$-value 0,001

Pasien dengan gastritis akan rentan merasakan nyeri ulu hati atau nyeri epigastrium (Raghavan dan Holmgren, 2012). Salah satu tatalaksana dari manajemen nyeri adalah guide imagery. Menurut Potter \& Perry (2005), bahwa "Guided imagery adalah proses yang menggunakan kekuatan pikiran untuk menyembuhkan diri dan memelihara kesehatan atau rileks melalui komunikasi dalam tubuh".
Menurut Utari \& Kartika (2018), bahwa "Guide imagery merupakan suatu imajinasi yang dirancang secara khusus untuk mencapai efek positif yaitu dengan membayangkan hal-hal yang menyenangkan yang kemudia akan terjadi perubahan aktivitas motoric sehingga otot-otot yang tegang akan menjadi relaks, sehingga respin terhadap bayangan menjadi semakin jelas". Selanjutnya dalam Utari \& Kartika (2018), bahwa "Perasaan relaks ini terjadi karena rangsangan imajinasi berupa hal-hal yang menyenangkan akan dijalankan kebatang otak menuju sensor thalamus untuk di format, kemudian sebagian kecil rangsangan itu ditransmisikan ke amigdala dan hipokampus, sebagian lagi dikirim ke korteks serebi hingga akan terjadi asosiasi pengindraan. Pada hipokampus hal hal yang menyenangkan akan diproses menjadi sebuah memori”.

Menurut Utari \& Kartika (2018), Kemudian dari "hipokampus ketika akan terdapat rangsangan Ketika terdapat rangsangan berupa imajinasi yang menyenangkan memori yang tersimpan akan muncul kembali dan menimbulkan suatu persepsi. Dari hipokampus rangsangan yang telah mempunyai makna dikirim ke amigdala yang akan membentuk pola respon yang sesuai dengan makna rangsangan yang diterima. Sehingga subjek akan lebih mudah untuk mengasosiasikan dirinya dalam menurunkan sensasi nyeri yang di alami. Guide imagery memiliki efek membuat responden merasa rileks dan tenang yaitu ketika responden menjadi rileks dan tenang saat mengambil oksigen di udara melalui hidung, oksigen masuk ke dalam tubuh sehingga aliran darah menjadi lancer serta dikombinasikan dengan imajinais terbimbing menyebabkan seseorang mengalihkan perhatiannya yang 
membuatnya senang dan bahagia sehingga melupakan nyeri yang dialaminya".

Hal ini sejalan dengan penelitian yang dilakukan oleh Lolo \& Noviyanti (2018), bahwa "terdapat pengaruh pemberian guided imagery terhadap skala nyeri pada pasien post operasi appendicitis hari pertama di RSUD Sawerigading Kota Palopo Tahun 2017, dengan nilai pvalue 0,000". Penelitian lain yang mendukung adalah penelitian dari Zulfa (2020), yaitu dengan "pengaruh guided imagery terhadap penurunan skala nyeri pasien post operasi di ruang rawat inap bedah rsud dr. H. Abdul moeloek provinsi lampung tahun 2020, terdapat pengaruh dengan nilai $p$-value 0,000 ".

\section{SIMPULAN}

Kesimpulan dalam penelitian ini adalah mayoritas pasien gastritis di RSU Royal Prima memiliki jenis kelamin perempuan, berusia 18-45 tahun, memiliki pendidikan SMA, mayoritas memiliki riwayat pekerjaan karyawan swasta, dan lama rawat inap 2 hari. Sedangkan skala nyeri pasien mayoritas memiliki skala nyeri sedang-berat sebelum intervensi. Terdapat pengaruh guide imagery terhadap penurunan rasa nyeri pasien gastritis di RSU Royal Prima dengan nilai sig. 2 tailed $0,000<$ 0,05 .

\section{DAFTAR PUSTAKA}

Afdila, J.N. (2016). Pengaruh Terapi Guided Imagery terhadap Tingkat Stress pada Mahasiswa Tingkat Akhir dalam Menyelesaikan Skripsi. Skripsi. Surabaya: Universitas Airlangga. (tidak diterbitkan) http://repository.unair.ac.id/50614/ 13/50614.pdf diunduh pada tanggal 16 Februari 2018
Agustiar W. \& Asmi Y. (2010). Kecemasan menghadapi Ujian Nasional dan Motivasi Belajar Pada Siswa Kelas XIII SMA Negeri " $X$ " Jakarta Selatan. Jurnal Psikologi. Vol. 8, No. 1. $9-15$. http://download.portalgaruda.org/a rticle.php? article $=94852 \&$ val $=456$ 4 diunduh pada tanggal 14 Februari 2018

Alwisol. (2014). Psikologi Kepribadian. Malang: UMM Press Andri, Dewi.P. \& Yenny. (2007). Teori Kecemasan Berdasarkan Psikoanalisis Klasik dan Berbagai Mekanisme Pertahanan terhadap Kecemasan. Maj Kedokt Indon. Vol. 57, No. 7. 233 - 238. http://mki.idionline.org/index.php? uPage $=$ mki.mki_dl\&smod $=$ mki\&s $\mathrm{p}=\quad$ public\&key=MTM1LTEy diunduh pada tanggal 15 Februari 2018

Aprianto, D., Kristiyawati, S.P., \& Purnomo. (2013). Efektivitas Teknik Relaksasi Imajinasi Terbimbing dan Nafas Dalam Terhadap Penurunan Kecemasan Pada Pasien Pre Operasi. http://ejournal.stikestelogorejo.ac.i $\mathrm{d} /$ index.php/ilmukeperawatan/artic le/ view/166/190 diunduh pada 14 Februari 2018

Bertini, M.A. (2001). The Effects of Guided Imagery and Music on Anxiety. Dissertation. Faculty of Holos University. (tidak diterbitkan) https://www.holosuniversity.org/u ploads/4/3/4/3/43432007/bertini_di ss. pdf diunduh pada tanggal 14 Februari 2018

Deswita, Ns., Asterina, \& Hikmah, U. (2014). Pengaruh Teknik Relaksasi Imajinasi Terbimbing (Guided 
Imagery) Terhadap Pemenuhan Kebutuhan Tidur Anak Usia Sekolah di Ruang Rawat Inap Anak RSUD Prof. Dr. Ma. Hanafiah SM Batusangkar. Jurnal Keperawatan. Vol. 10, No. 1. 110 - 117. http://ners.fkep.unand.ac.id/index. $\mathrm{php} /$ ners/article/download/36/31 diunduh pada tanggal 15 Februari 2018

Fausiah, F. \& Widury, J. (2006). Psikologi Abnormal Klinis Dewasa. Jakarta: Penerbit Universitas Indonesia.

Bruckenthal. (2010). Integrating Nonpharmacologic and Alternative Strategies into A Comprehensive Management Approach for Older Adult with Pain, Pain Manog Nurs

Handayani, Sari. (2018). Pengaruh Guide Imagery Terhadap Respon Nyeri Pasien Remathoid Artritis di Komunitas. Skripsi.

Kozier, B. (2010). Fundamental of nursing. Concepts, process and practice. (8th ed), california: Addison-wesley.

Notoatmodjo, S. (2012). Metodologi penelitian kesehatan. Jakarta: Rineka Cipta

Nursalam. (2013). Metodologi penelitian ilmu keperawatan: pendekatan praktis edisi 3. Jakarta: Salemba Medika.

Patasik, C., K., Tangka, C., \&Rottie, J. (2013).Efektifitas Teknik Relaksasi Nafas Dalam Dan Guided Imagery Terhadap Penurunan Nyeri Pada Pasien Post Operasi apendisitis Di Irina D Blu RSUP Prof. Dr. R. D. Kandou
Manado. Ejurnal keperawatan (eKp) Volume 1.Nomor 1.Diakses bulan Maret 2018, https://ejournal. unstrat.ac.

id/indeks.php/jkp/article/viewFile/ 2169/1727

Potter \& perry. (2010). Fundamental keperawatan. Edisi 7. Jakarta : Salemba medika

Sembiring, Robbialwy., Ema Novelia, Merisusanna Sinuhaji, \& Chrismis Novalinda Ginting. (2019). Pengaruh Guided Imagary Terhadap Penurunan Rasa Nyeri Pada Penderita Gastritis Di Rumah Sakit Umum Royal Prima Medan : Malahayati Nursing Journal.

Utami, A.D. \& Kartika, I.R. (2018). Terapi Komplementer Guna Menurunkan Nyeri Pasien Gastritis: Literatur Review. REAL in Nursing Journal (RNJ), Vol. 1, No. 3.

World Health Organization (WHO) 2014. Commission on Ending Childhood Obesity. Geneva, World Health Organization, Departement of Noncommunicable disease surveillance 
Jurnal Penelitian Perawat Profesional, Volume 3 No 1 Hal 199 - 206, Februari 2021 Global Health Science Group 